\title{
Inhibition of Oxygen-induced Retinal Neovascularization in the Neonatal Rat by Green Tea Extract
}

\author{
Masayuki Minami, ${ }^{1}$ Yasuko Hasebe, ${ }^{1}$ Takako Nakanishi-Ueda, ${ }^{2, *}$ Sinichi Iwai, ${ }^{2}$ \\ Toshihiko Ueda, ${ }^{1}$ C. Kathleen Dorey, ${ }^{3}$ Katsuji Oguchi, ${ }^{2}$ Hajime Yasuhara, ${ }^{2}$ and \\ Ryohei Koide ${ }^{1}$ \\ ${ }^{1}$ Department of Ophthalmology, School of Medicine, Showa University, Tokyo 142-8555, Japan \\ ${ }^{2}$ Department of Pharmacology, School of Medicine, Showa University, Tokyo 142-8555, Japan \\ ${ }^{3} R \& D$ Consulting, 15 Draper Avenue, Arlington, Massachusetts 02474, USA
}

Received 11 November, 2002; Revised 8 January, 2003; Accepted 21 January, 2003

\begin{abstract}
Summary To investigate the effect of green tea extract (GTE) on oxygen-induced neovascularization (NV) in neonatal rat model, NV was induced by maintaining neonatal rats in $80 \%$ oxygen on a cycle of $23.5 \mathrm{~h}$ oxygen/0.5 h room air until postnatal day 12 (P12), when the rats were placed in room air. The control rats were maintained in room air. From $\mathrm{P} 6$ to P17, rats were treated once daily by oral administration of saline $(50 \mu 1 / 10 \mathrm{~g}$ body weight $)$ that contained $25 \%$ GTE, $12.5 \%$ GTE, or nothing. On P18, the rats were sacrificed and the retinal samples were collected. Retinal NV was scored and avascular areas (AVAs) were measured in ADPase stained retinas. The retinal vascular endothelial cell growth factor (VEGF) contents were measured with immunoassay kit, and matrix metalloproteinase-2 (MMP-2) activity was determined by gelatin zymography. GTE (25\%) treatment suppressed NV and slightly increased AVAs in oxygen-induced NV model compared with the control. VEGF contents in retina significantly increased on P13 and P15, but GTE treatment did not prevent the increase of VEGF contents. Oxygen-induced increases in MMP-2 activity on P13 and P15 were suppressed by GTE treatment. These results suggest that GTE suppressed oxygen-induced NV in the neonatal rat, possibly through inhibition of MMP-2 activity. It also suggests that orally administered green tea has the potential to inhibit neovascular disease.
\end{abstract}

Key Words: neovascularization, oxygen-induced retinopathy, green tea, matrix metalloproteinase, vascular endothelial cell growth factor

\section{Introduction}

Retinal neovascularization (NV) is the final common pathway to sight threatening disease including retinopathy of prematurity, diabetic retinopathy and age related macular degeneration $[1,2]$. Oxygeninduced retinopathy (OIR) of rodents provides a

*Correspondence to: T. Nakanishi-Ueda

Tel: +81-3-3784-8128 Fax: +81-3-3784-8129

E-mail: tachueda@med.showa-u.ac.jp. good model system for studying retinal neovascular disease [3]. The underlying mechanism of OIR is not fully understood. Angiogenic stimulators such as vascular endothelial growth factor (VEGF), insulinlike growth factor 1 and/or retinal hypoxia have been found to play a role in oxygen-induced retinal NV [4-6]. Green tea is widely consumed in the eastern world, especially in Japan and China, where it has also been utilized as an herbal medicine. Epidemiologic studies have suggested that consumption of green tea may help prevent some types of cancer $[7$, 
$8]$, but not others $[9,10]$. The major components in green tea are polyphenols, known as catechins, caffeine and flavonols. The predominant catechin, (-)epigallocatechin gallate (EGCG) is an effective antioxidant, reacting with most reactive oxygen species $[11,12]$. Several lines of evidence suggest that green tea and/or EGCG have anti-angiogenic properties. $\mathrm{Cao}$ and $\mathrm{Cao}$ [13] demonstrated that EGCG inhibited angiogenesis in chick chorioallantonic model and that drinking tea inhibited VEGF-induced corneal NV in mice. Garbisa et al. $[14,15]$ showed that EGCG suppressed the activity of matrix metalloproteinases (MMPs), and blunted tumor invasion. Furthermore, Bertolini et al. [16] reported that green tea inhibited angiogenesis and induced endothelial and tumor cell apoptosis in animal model of human high-grade non-Hodgkin's lymphoma. Recently, Sartippour et al. $[17,18]$ reported that EGCG inhibited protein and mRNA expression of VEGF, and fibroblast growth factors 1 and 2 by human breast cancer cells and by human umbilical vein endothelial cells in vitro.

In this study, we investigated whether orally administered green tea extract (GTE) or EGCG could inhibit oxygen-induced retinal NV in neonatal rats and whether NV correlated with levels of VEGF and MMPs.

\section{Material and Methods}

All experiments were performed in accordance with ARVO Statement for the Use of Animals in Ophthalmic and Vision Research and approved by the institutional committee of animal care and use at our institution.

\section{Animal model}

Sprague-Dawley neonatal rats (Clea Japan Co., Tokyo, Japan) were used. For each experiment, 12 or 13 neonatal rats were kept with a mother rat in each cage. Mother rats were rotated between the oxygen and room air environments every two days within the experimental period. NV was induced in neonatal Sprague-Dawley rats by our standard protocol [3, 19]. Briefly, neonates were exposed from birth to day 12 (P12) to daily cycles of $80 \%$ oxygen $(20.5 \mathrm{~h}$ ), room air $(0.5 \mathrm{~h})$ and progressive return to $80 \%$ oxygen $(3 \mathrm{~h})$; on $\mathrm{P} 12$, the rats were placed in room air until P18. For each experiment, 12 or 13 neonates were caged with each mother rat in oxygen or room air.

\section{Treatment schedule}

GTE $(12.5 \%$ or $25 \%)$ in saline, EGCG $(2 \mathrm{mg} / 50$ $\mu 1)$ in saline, or saline alone was given orally to animals in a constant volume of $50 \mu 1 / 10 \mathrm{~g}$ body weight once daily from P6 to P17.

\section{Preparation of green tea extracts}

Organic green tea leaves with no preservation (Mouriseicha, Kyoto, Japan) were obtained commercially. GTE were prepared as previously described [20] by flooding green tea leaves with saline (12.5 or $25 \mathrm{~g}$ tea leaves in $100 \mathrm{ml}$ saline, $\mathrm{pH}$ 6.3) for $3 \mathrm{~h}$ at room temperature, and then filtering the sediments out.

\section{$E G C G$}

EGCG (Sigma, St. Louis, MO, USA) was prepared at $40 \mathrm{mg} / \mathrm{ml}$ in saline, a concentration that corresponds to $25 \%$ ( $25 \mathrm{~g} / 100 \mathrm{ml}) \mathrm{GTE}$.

\section{Retinal processing and analysis}

On P18, the rats were sacrificed by i.p. injection of $0.3 \mathrm{ml}$ of sodium pentobarbital $(50 \mathrm{mg} / \mathrm{ml})$ and the retinal samples were fixed, stained for adenosine diphosphatase (ADPase), and flatmounted as previously described [3]. Retinal NV was scored using the method of Hasebe et al. [19] (Table 1). Avascular areas (AVAs) were measured in ADPase stained retinas. Digital images of the mounted ADPase stained retinas were obtained using a camera and scanner (Nikon, Tokyo, Japan). Avascular and total retinal areas were measured using $\mathrm{NIH}$ image software

Table 1. Criteria for neovascular score ( NV Score).

\begin{tabular}{cl}
\hline $\begin{array}{c}\text { Score } \\
\text { (In each quadrant) }\end{array}$ & \multicolumn{1}{c}{ Characteristics of neovascularization } \\
\hline 0 & None observed \\
1 & Less than five glomerular buds \\
2 & Five or more buds or a frond \\
3 & Short ridge (neovascular ridges extending less than halfway across a quadrant) \\
4 & Long ridge (neovascular ridges extending at least halfway across a quadrant) \\
\hline
\end{tabular}


(National Institutes of Health, Bethesda, MD, USA). The mean percentages of AVAs in the total retinal area (\%AVAs) were calculated.

\section{Quantification of VEGF protein}

On P12, P13, P15, and P18, retinal samples were collected and stored at $-70^{\circ} \mathrm{C}$ till analysis. The sample and $100 \mu 1 \mathrm{H}_{2} \mathrm{O}$ were submerged in crushed ice, sonicated with $5 \mathrm{~s}$ bursts at $40 \mathrm{~W}$ (Branson Sonifier Cell Disruptor 200, Branson, Rochester Hills, MI, USA), and centrifuged at $3,000 \mathrm{rpm}$ for $10 \mathrm{~min}$. VEGF in the supernatant was assayed by using a Quantikine immunoassay kit (R\&D Systems Inc., Minneapolis, MN, USA). Protein concentrations were determined by the method of Lowry et al. [21] with bovine serum albumin as standard.

\section{Measurement of MMP activities}

MMP-2 and -9 were measured by gelatin zymography on $10 \%$ polyacrylamide gels containing $1 \mathrm{mg} /$ $\mathrm{ml}$ gelatin in a polymerization mixture of SDS. The frozen retinas were sonicated and centrifuged as described above. Samples containing equal protein concentrations $(15 \mu \mathrm{g})$ were mixed with saline. For detection of proteinases, SDS was washed out of the gels with $2.5 \%$ triton $\mathrm{X}-100$ for $30 \mathrm{~min}$ at room temperature before incubation at $37^{\circ} \mathrm{C}$ for 1 day in a solution containing $50 \mathrm{mM}$ Tris- $\mathrm{HCl}, \mathrm{pH} 7.5 ; 5 \mathrm{mM}$ $\mathrm{CaCl}_{2}$; and $0.02 \%$ sodium azide. Gels were stained with $0.1 \%$ Coomassie blue in $10 \%$ acetic acid and $50 \%$ methanol for $30 \mathrm{~min}$, and then de-stained in $10 \%$ acetic acid and 50\% methanol. Clear areas indicated proteolytic activity [22]. Molecular weight standards (Sigma) were included to calibrate the gels. The $72 \mathrm{kDa}$ purified human proenzyme MMP2 (pro-form; pro-MMP-2), the $62 \mathrm{kDa}$ purified proenzyme MMP-2 (active-form; active-MMP-2) and the $92 \mathrm{kDa}$ purified proenzyme MMP-9 were used as a positive control and standard for the gels (Oncogene Research Products, San Diego, CA, USA). The zymography bands were digitized using Gel Doc/Chemic Doc Imaging System (Bio Rad, Herculus, CA, USA) and the data analyzed using the Quantify One analysis software program (Bio $\mathrm{Rad})$. Total protein was measured in the retina samples using the BCA Assay (Pierce Chemical Co., Rockford, IL, USA) with bovine serum albumin as the standard.

\section{Statistics}

Statistical analysis was performed by using ANOVA or Mann-Whitney U-Test. All data are expressed as a mean \pm standard error (SE) and differences were considered significant when $p<0.05$.
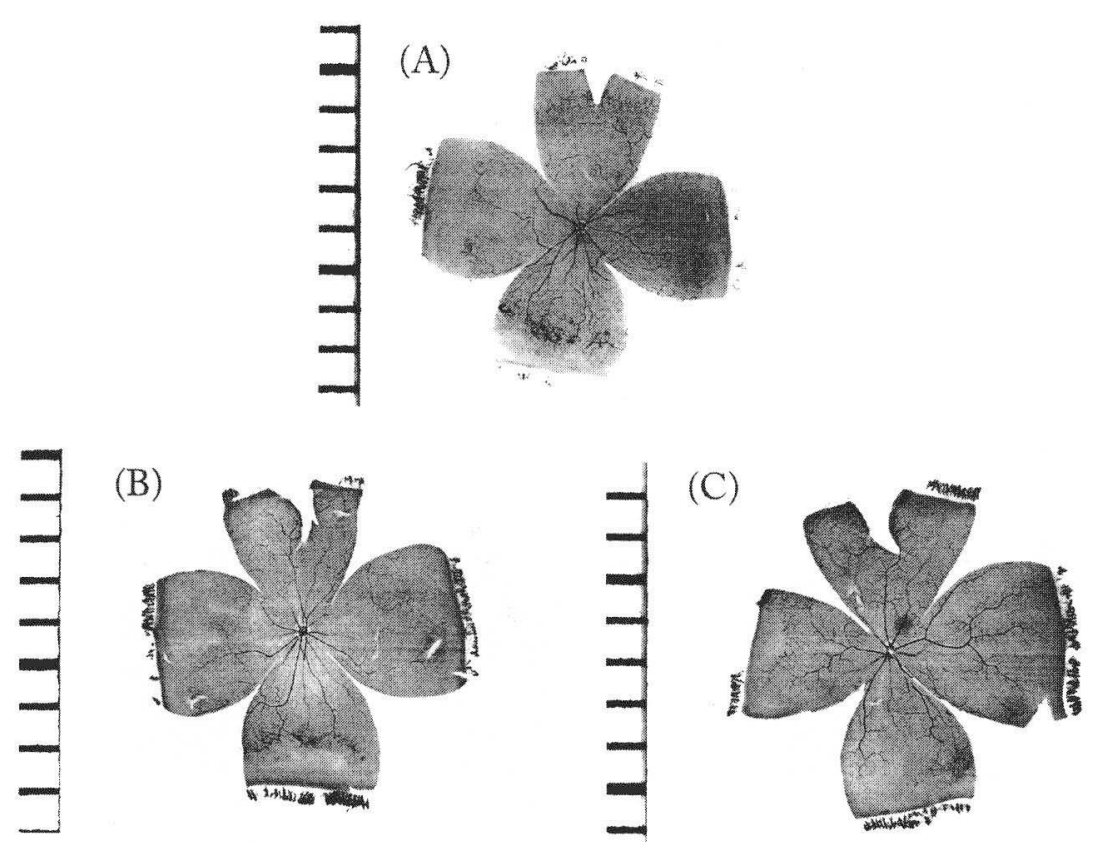

Fig. 1. ADPase stained retina. (A) control group. NV score is $8 \%$ AVAs is $14.6 \%$. (B) $12.5 \%$ GTE treated group. NV score is $5 \%$ AVAs is $12.9 \%$. (C) $25 \%$ GTE treated group. NV score is $4 \%$ AVAs is $5.0 \%$. 


\section{Results}

Rats treated with either GTE or EGCG did not show growth retardation compared with controls in room air or $80 \%$ oxygen exposure. Normal retinal vasculature was seen in the animals raised in roomair. Oxygen-exposed retinas exhibited neovascular changes and retained avascular areas, as seen in Fig. 1.

The NV scores and \%AVAs in the EGCG-treated and control groups were not significantly different from the saline treated control (Fig. 2). In EGCG treated and controls, $\mathrm{NV}$ scores were $4.6 \pm 1.1$ and 4.2 \pm 0.7 , respectively, and \%AVAs were $25.2 \pm 4.7 \%$ and $17.8 \pm 4.0 \%$, respectively.

In contrast, animals treated with the $25 \%$ GTE had NV scores that were 39\% lower than those in the untreated controls (Fig. 3). NV scores in the $25 \%$
(A)

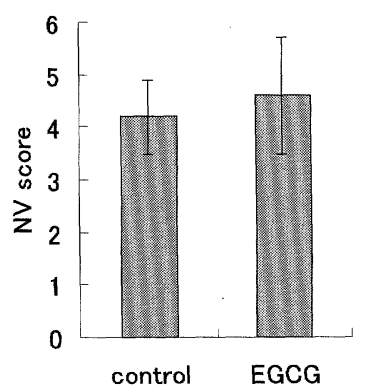

(B)

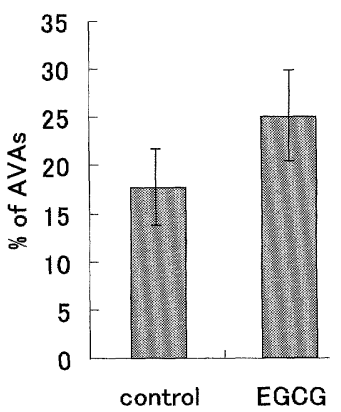

Fig. 2. Effect of EGCG treatment on the oxygen-induced retinal $\mathrm{NV}$ in the neonatal rat.

(A) NV score, (B) \%AVAs. Data represent mean \pm SE for control group $(n=10)$ and EGCG treated group $(n=10)$. The significant differences were not observed between control and EGCG treated groups.

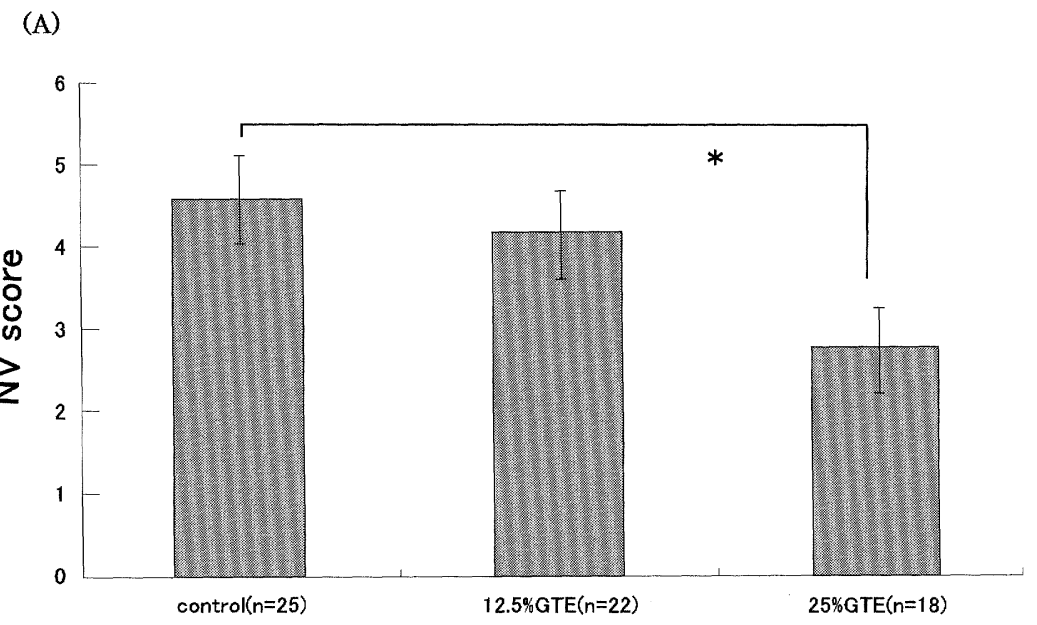

(B)

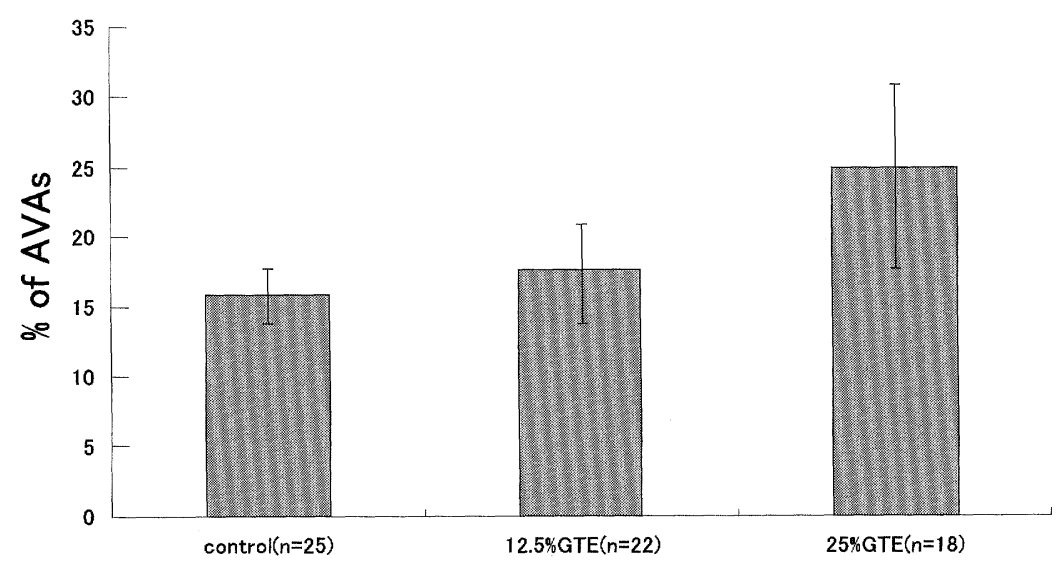

Fig. 3. Effect of GTE treatment on oxygen-induced retinal NV in the neonatal rat. (A) NV score, (B) \%AVAs. Data represent mean \pm SE. In GTE $(25 \%)$-treated groups, NV score is significantly lower than saline controls $\left({ }^{*} p=0.05\right.$; ANOVA). 


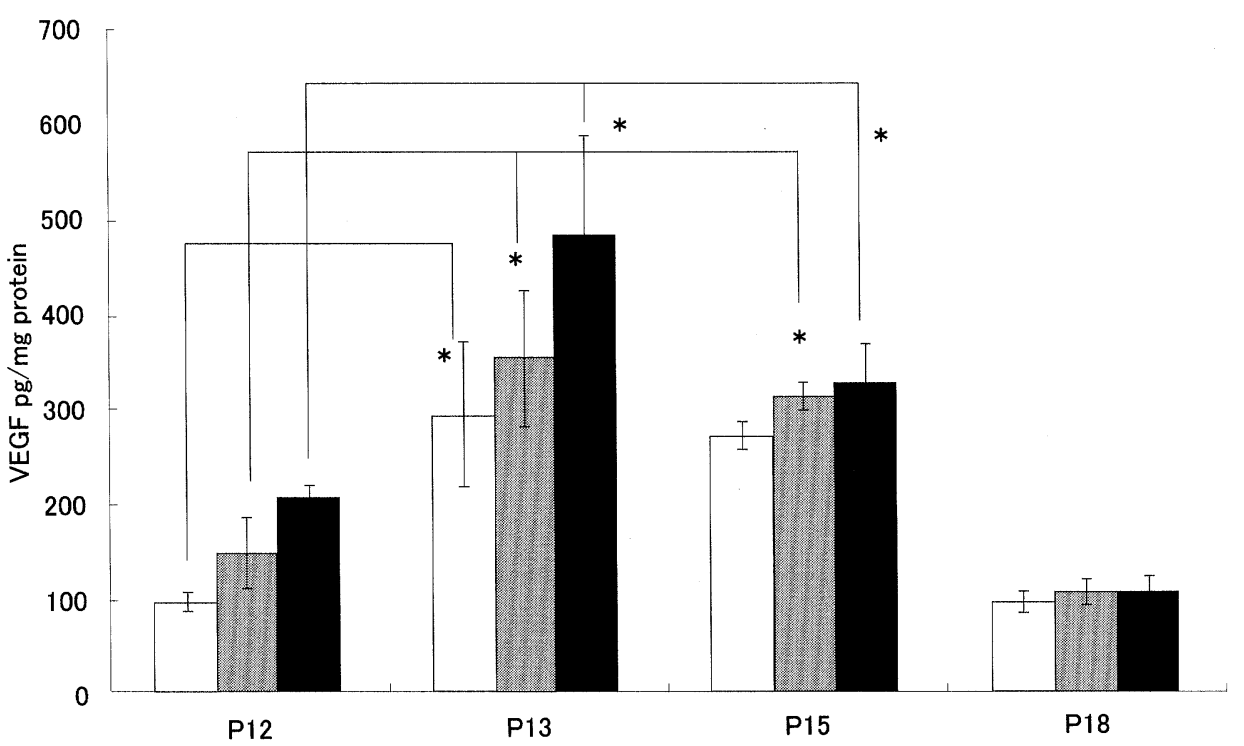

Fig 4. Effect of GTE treatment on VEGF contents in retina after oxygen exposure. Data represent $\mathrm{mean} \pm \mathrm{SE}(\mathrm{pg} / \mathrm{mg}$ protein, $n=3$ for each point). The content of VEGF significantly increased at day 13 in each group ( $\square$, control; $\square$, 12.5\% GTE; $\mathbf{\square}$, 25\% GTE; $p=0.05$, Mann-Whitney U-test) and at day 15 in $12.5 \%$ and $25 \%$ GTE compared with day 12 .

Table 2. Effect of GTE treatment on MMP-2 activities in retina.

\begin{tabular}{|c|c|c|c|c|c|c|c|}
\hline & \multicolumn{3}{|c|}{$\mathrm{O}_{2}$ treatment } & \multicolumn{4}{|c|}{ Room air } \\
\hline & Saline & $12.50 \%$ & $25 \%$ & Saline & $12.50 \%$ & $25 \%$ & None \\
\hline \multicolumn{8}{|l|}{ P13 } \\
\hline pro- & 181 & 151 & 149 & 105 & 107 & 101 & 100 \\
\hline active- & 177 & 83 & 119 & 79 & 79 & 83 & 100 \\
\hline \multicolumn{8}{|l|}{ P15 } \\
\hline pro- & 145 & 98 & 91 & 90 & 90 & 95 & 100 \\
\hline active- & 192 & 161 & 143 & 66 & 60 & 64 & 100 \\
\hline
\end{tabular}

Relative activity of MMP-2 normalized to room air vehicle controls.

GTE treated group were significantly lower than those treated with the $12.5 \%(p=0.05$; ANOVA). The \%AVAs was also substantially higher in these animals than in the controls $(25.0 \pm 6.1 \%$ vs. $15.0 \pm 1.9 \%)$ but the differences were not significant. Treatment with the $12.5 \%$ GTE had no significant effect on NV scores or on \%AVAs.

The quantity of VEGF protein in the oxygentreated retinas increased significantly on $\mathrm{P} 13$ i.e. one day after removal from oxygen $(p=0.05$; MannWhitney U-Test), then declined gradually from P13 through P18. Higher quantities of VEGF were observed in the GTE-treated retinas on P12 and $\mathrm{P} 13$, but the differences did not achieve significance between control and GTE-treated groups (Fig. 4).

Figure 5 shows zymography of P13, 15, and 18 day old retinas. Pro-MMP-2 and active-MMP-2 were higher in oxygen-exposed retinas than in controls on P13 (A, 181\%, and 177\% of control, respectively) and on P15 (B, 144\% and 192\% of control, respectively), but not on $\mathrm{P} 18$. These increases on P13 and P15 were suppressed by GTE treatment (Table 2). MMP-9 was not clearly observed in these experiments.

\section{Discussion}

Here we showed that orally administered GTE suppressed $\mathrm{NV}$ in oxygen-exposed neonatal rats. In addition, we found that purified EGCG, the major tea catechin, had no effect on NV.

Pierce et al. [23] showed that VEGF protein and its mRNA increased between 6 and $12 \mathrm{~h}$ of relative retinal hypoxia and remained elevated during the 


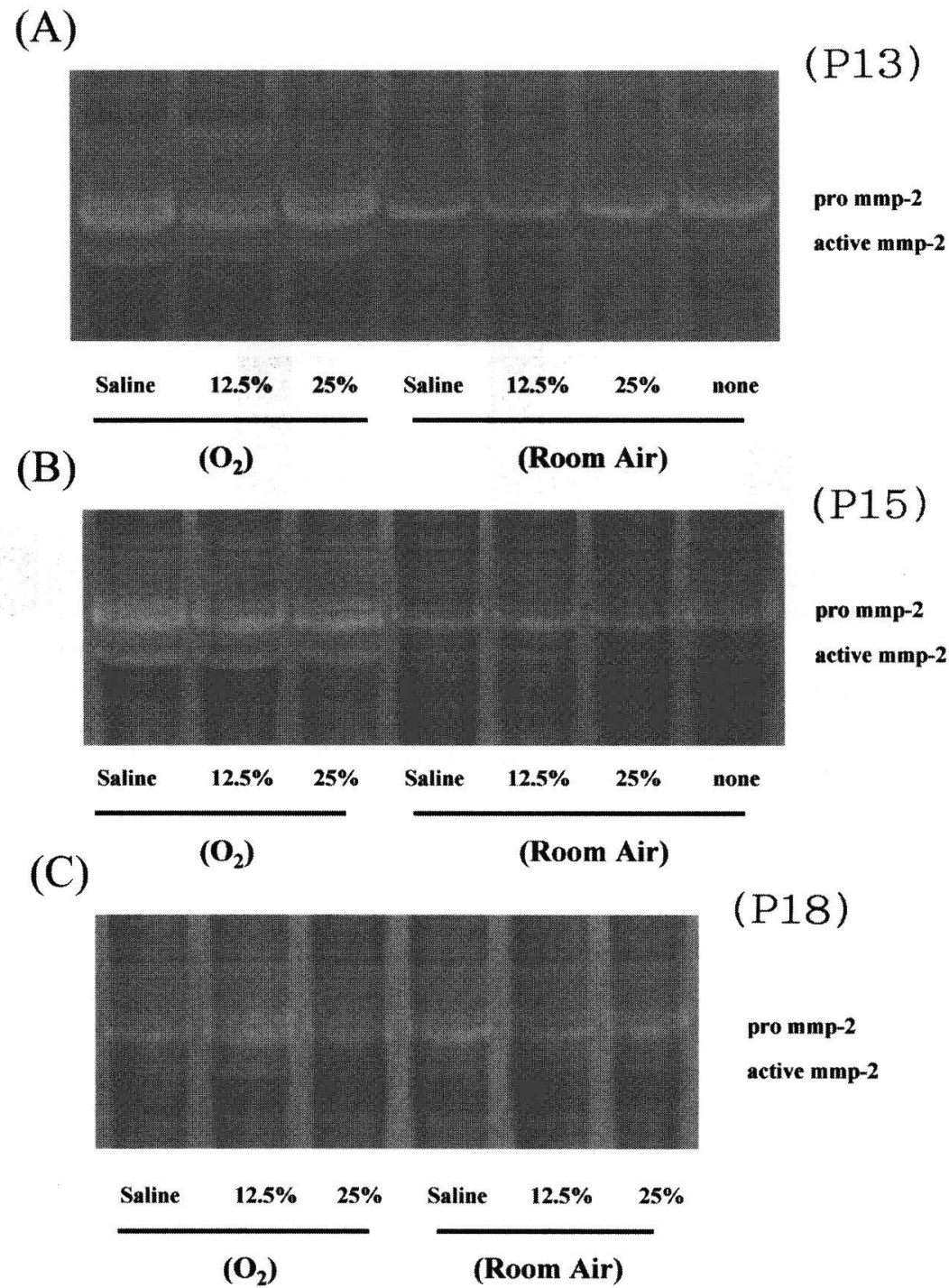

Fig. 5. Gelatin zymogram of retina, illustrating the elevated production of MMP-2 on P13 (A) and P15 (B) in oxygenexposed animals. However, by P18 the MMP-2 production returned to levels seen in room air animals. The elevated production of MMP-2 was suppressed by GTE treatment on P13 and P15.

development of NV in murine OIR. Kondo et al. [24] has shown that tea catechins inhibit human endothelial cell growth, migration and tube formation, through inhibition of VEGF receptor binding and Lamy et al. [25] further found that catechins suppress VEGF receptor phosphorylation. Similarly, we found that VEGF protein was elevated by oxygen exposure, and decreased following removal from oxygen. The higher levels of VEGF found in animals treated with $25 \%$ GTE was consistent with the larger AVAs observed in them. The effect of GTE on \%AVAs and on NV scores could both be explained by GTE-inhibition of the VEGF receptor activity $[24,25]$. A drug that inhibited VEGF receptor kinases, protein kinase $\mathrm{C}$ and other kinases inhibited both retinal vascular development and NV in murine OIR [26]. Potent inhibition of VEGF receptor-2 phosphorylation by GTE, catechins or other polyphenols could explain reduced NV scores in animals treated with $25 \%$ GTE. In dogs [27] and in mice [28], VEGF receptor-2 is preferentially associated with NV, and NV can be suppressed by inhibiting VEGF receptor-2. The larger AVAs observed in these animals suggest that the catechins may also suppress activity of VEGF receptor-1, which is expressed in normal retinal vessels [29].

It is possible that complex formation between EGCG and other components in decaffeinated 
green tea (DGT) may increase the absorption of EGCG. Chen et al. [30] reported that when administered orally EGCG in DGT showed a 3.6-fold higher absorption rate constant than pure EGCG in male Sprague-Dawley rats. And the $\mathrm{C}_{\max }$ were $16.3 \pm 6.5 \mathrm{ng} / \mathrm{ml}(0.036 \mu \mathrm{M})$ and $19.8 \pm 3.5 \mathrm{ng} / \mathrm{ml}$ $(0.043 \mu \mathrm{M})$, after EGCG $(14.6 \mathrm{mg} / \mathrm{kg})$ in DGT $(200 \mathrm{mg} / \mathrm{kg})$ and pure EGCG $(75 \mathrm{mg} / \mathrm{kg})$ oral administration. Following their report, we could calculate that the $\mathrm{C}_{\max }$ of EGCG in our oxygeninduced neonatal rat models; $223.3 \mathrm{ng} / \mathrm{ml}(0.487$ $\mu \mathrm{M})$ and $53.5 \mathrm{ng} / \mathrm{ml}(0.116 \mu \mathrm{M})$ after $25 \% \mathrm{GTE}$ or $40 \mathrm{mg} / \mathrm{ml}$ EGCG treatment, respectively. Therefore, treatment with a comparable dose of EGCG (40 $\mathrm{mg} / \mathrm{ml}$ ) did not prevent NV or alter AVAs. On the other hand, Cao and Cao [13] reported that orally administered tea inhibited VEGF-stimulated NV in the mouse corneal model. The blood concentration of EGCG in the mouse corneal model $(0.1-0.3 \mu \mathrm{M})$ was similar to our results. There were also reported that epigallocatechin (EGC), which is contained in GTE, reduced IL-8 production and inhibited tube formation in vitro using a model in which human microvascular endothelial cells [31]. It may be one of the inhibition mechanisms in this OIR model. The quantity of green tea administered in the $25 \%$ GTE treatments would correspond to a person drinking 1.5 liters of tea/day. Thus identification of the factor present in green tea would greatly facilitate further exploration of their therapeutic effect on NV, and provide a means to deliver effective doses in human subjects.

It has been firmly established that MMPs are required for angiogenesis and tumorigenesis $[32,33]$. When endothelial cells are cultured on matrigel, the formation of tubular networks is increased by the addition of recombinant MMP-2 and decreased when neutralizing antibody or tissue inhibitor of MMP-2 (TIMP-2) is added [34]. MMP-2 deficient mice are reported to have reduced tumor-induced and corneal angiogenesis $[35,36]$.

Garbisa et al. $[14,15]$ showed that EGCG directly suppressed the activity of MMP-2 and MMP-9. Annabi et al. [37] reported EGCG inhibited MMP2 secretion. Demeule et al. [38] reported that green tea polyphenol, and more particularly EGCG, inhibited the activity of various MMPs as well as the activation of pro-MMP-2 activation. On the other hand, EGCG inhibits membrane-type 1 MMP (MT1-MMP) activity [39] or urokinase type plasminogen activator (uPA) activity [40], those are important factors of pro-MMP-2 activation, leading to decrease of active-MMP-2. Therefore, these data suggest that GTE-treatment suppressed the oxygeninduced increases in pro-MMP-2 and active-MMP2 by through the inhibition of MMP-2 secretion, and active-MMP-2 formation. Our data propose that green tea may also inhibit $\mathrm{NV}$ by reducing MMP-2 activity.

We cannot exclude the possibility that the GTE may have acted through its antioxidant activity [41, 42], quenching reactive oxygen intermediates that increase VEGF expression in vitro and during the reperfusion of ischemic retina in vivo [43]. Our group has reported that lipid hydroperoxide-induced $\mathrm{NV}$ in rabbit cornea could be inhibited by both a combination of antioxidants (EPC-K1; vitamins $\mathrm{E}$ and C compound) [44], and by Sairei-to, a compound with antioxidant activity in vitro [45].

In conclusion, more than one component of GTE may influence oxygen-induced retinal NV. These results suggest that orally administered green tea has the potential to slow neovascular disease such as the diabetic retinopathy and the retinopathy of prematurity.

\section{Acknowledgment}

The authors thank Ms. E. Ozawa for her technical assistance.

\section{References}

[1] Folkman, J.: Angiogenesis in cancer, vascular, rheumatoid and other disease. Nat. Med., 1, 27-31, 1995.

[2] Lee, P., Wang, C.C., and Adamis, A.P.: Ocular neovascularization: an epidemiologic review. Surv. Ophthalmol., 43, 245-269, 1998.

[3] Reynaud, X. and Dorey, C.K.: Extraretinal neovascularization induced by hypoxic episodes in the neonatal rat. Invest. Ophthalmol. Vis. Sci., 35, 3169-3177, 1996.

[4] Smith, L.E., Wesolowski, E., McLellan, A., Kostyk, S.K., D'Amato, R., Sullivan, R., and D'mare, P.A.: Oxygen-induced retinopathy in the mouse. Invest. Ophthalmol. Vis. Sci., 35, 101-111, 1994.

[5] Smith, L.E., Shen, W., Perruzzi, C., Soken, S., Kinose, F., Xu, X., Robinson, G., Driven, S., Bischoff, J., Zhang, B., Schaeffen, J.M., and Sengen, D.R.: Regulation of vascular endothelial growth factordependent retinal neovascularization by insulin-like growth factor-1 receptor. Nat. Med., 5, 1390-1395, 1999.

[6] Ozaki, H., Yu, A.Y., Della, N., Ozaki, K., Luna, J.D., Yamada, H., Hackett, S.F., Okamoto, N., Zack, D.J., Semenza, G.L., and Campochiaro, P.A.: Hypoxia inducible factor-1alpha is increased in ischemic retina: 
temporal and spatial correlation with VEGF expression. Invest. Ophthalmol. Vis. Sci., 40, 182-189, 1999.

[7] Gao, Y.T., McLaughlin, J.K., Blot, W.J., Ji, B.T., Dai, Q., and Fraumeri, J.F.: Reduced risk of esophageal cancer associated with green tea consumption. J. Natl. Cancer Inst., 86, 855-858, 1994.

[8] Zhang, M., Binns, C.W., and Lee, A.H.: Tea consumption and ovarian cancer risk: a case-control study in China. Cancer Epidemiol. Biomarkers Prev., 11, 713$718,2002$.

[9] Lee, H.H., Wu, H.Y., Chuang, Y.C., Chang, A-S., Chao, H-H., Chen, K-Y., Chen, H-K., Lai, G-H., Huang, H-H., and Chen, C-J.: Epidemiologic characteristics and multiple risk factors of stomach cancer in Taiwan. Anticancer Res., 10, 875-881, 1990.

[10] Hoshiyama, Y., Kawaguchi, T., Miura, Y., Mizoue, T., Tokui, N., Yatsuya, H., Sakata, K., Kondo, T., Kikuchi, S., Toyoshima, H., Hayakawa, N., Tamakoshi, A., Ohno, Y., and Yoshimura, T.: A prospective study of stomach cancer death in relation to green tea consumption in Japan. Br. J. Cancer, 87, 309-313, 2002.

[11] Bravo, L.: Polyphenols: chemistry, dietary sources, metabolism, and nutritional significance. Nutr. Rev., 56, 317-333, 1998.

[12] Yang, C.S., Maliakal, P., and Meng, X.: Inhibition of carcinogenesis by tea. Annu. Rev. Pharmacol. Toxicol., 42, 25-54, 2002.

[13] Cao, Y. and Cao, R.: Angiogenesis inhibited by drinking tea. Nature, 398, 381, 1999.

[14] Garbisa, S., Biggin, S., Cavallarin, N., Sartor, L., Benelli, R., and Albini, A.: Tumor invasion: molecular shears blunted by green tea. Nat. Med., 5, 1216, 1999.

[15] Garbisa, S., Sartor, L., Biggin, S., Salvato, B., Benelli, R., and Albini, A.: Tumor gelatinases and invasion inhibited by the green tea flavonol epigallocatechin-3gallate. Cancer, 91, 822-832, 2001.

[16] Bertolini, F., Fusetti, L., Rabascio, C., Cinier, S., Martinelli, G., and Pruneri, G.: Inhibition of angiogenesis and induction of endothelial and tumor cell apoptosis by green tea in animal models of human high-grade non-Hodgkin's lymphoma. Leukemia, 14, 1477-1482, 2000.

[17] Sartippour, M.R., Shao, Z.M., Heber, D., Beatty, P., Zhang, L., Liu, C., Ellis, L., Liu, N., Go, V.L., and Brooks, M.N.: Green tea inhibits vascular endothelial growth factor (VEGF) induction in human breast cancer cells. J. Nutr., 132, 2307-2311, 2002.

[18] Sartippour, M.R., Heber, D., Zhang, L., Beatty, P., Elashoff, D., Elashoff, R., Go, V.L., and Brooks, M.N.: Inhibition of fibroblast growth factors by green tea. Int. J. Oncol., 21, 487-491, 2002.

[19] Hasebe, Y., Thomson, L.R., and Dorey, C.K.: Pentoxifylline inhibition of vasculogenesis in the neonatal rat retina. Invest. Ophthalmol. Vis. Sci., 41, 2774-2778, 2000.

[20] Toda, M., Okubo, S., Ohnishi, R., and Shimamura, T.: Antibacterial and bactericidal activities of Japanese green tea.Jpn.J. Bacteriol., 44, 669-672, 1989.

[21] Lowry, O.H., Rosebrough, N.J., Farr, A.L., and Randall, R.J.: Protein measurement with the folin phenol reagent. J. Biol. Chem., 193, 265-275, 1951.

[22] Grant, M.B., Caballero, S., Tarnuzzer, R.W., Bass, K.E., Ljubimon, A.V., Spoerri, P.E., and Galardy, R.E.: Matrix metalloproteinase expression in human retinal microvascular cells. Diabetes, 47, 1311-1317, 1998.

[23] Pierce, E.A., Avery, R.L., Foley, E.D., Aiello, L.P., and Smith, L.E.: Vascular endothelial growth factor/ vascular permeability factor expression in a mouse model of retinal neovascularization. Proc. Natl. Acad. Sci. USA, 92, 905-909, 1995.

[24] Kondo, T., Ohta, T., Igura, K., Hara, Y., and Kaji, K.: Tea catechins inhibit angiogenesis in vitro, measured by human endothelial cell growth, migration and tube formation, through inhibition of VEGF receptor binding. Cancer Lett., 180, 139-144, 2002.

[25] Lamy, S., Gingras, D., and Beliveau, R.: Green tea catechins inhibit vascular endothelial growth factor receptor phosphorylation. Cancer Res., 62, 381-385, 2002.

[26] Seo, M.S., Kwak, N., Ozaki, H., Yamada, H., Okamoto, N., Yamada, E., Fabbro, D., Hofman, F., Wood, J.M., and Campochiaro, P.A.: Dramatic inhibition of retinal and choroidal neovascularization by oral administration of a kinase inhibitor. Am. J. Pathol., 154, 1743-1753, 1999.

[27] Suzuma, K., Takagi, H., Otani, A., Suzuma, I., and Honda, Y.: Increased expression of KDR/Flk-1 (VEGFR-2) in murine model of ischemia-induced retinal neovascularization. Microvasc. Res., 56, 183191, 1998.

[28] McLeod, D.S., Taomoto, M., Cao, J., Zhu, Z., Witte, L., and Lutty, G.A.: Localization of VEGF receptor-2 (KDR/Flk-1) and effects of blocking it in oxygeninduced retinopathy. Invest. Ophthalmol. Vis. Sci., 43, 474-482, 2002.

[29] Witmer, A.N., Dai, J., Weich, H.A., Vrensen, G.F., and Schlingemann, R.O.: Expression of vascular endothelial growth factor receptors 1,2 , and 3 in quiescent endothelia. J. Histochem. Cytochem., 50, 767$777,2002$.

[30] Chen, L., Lee, M-J., Li, H., Yang, C.S.: Absorption, distribution, and elimination of tea polyphenols in rats. Drug Metabol. Dis., 25, 1045-1050, 1997.

[31] Tang, F.Y. and Meydani, M.: Green tea catechins and vitamin $\mathrm{E}$ inhibit angiogenesis of human microvascular endothelial cells through suppression of IL-8 production. Nutr. Cancer, 41, 119-125, 2001.

[32] Parsons, S.L., Watson, S.A., Brown, P.D., Collins, H.M., and Steele, R.J.: Matrix metalloproteinases. Br. J. Surg., 84, 160-166, 1997.

[33] Pepper, M.S.: Role of the matrix metalloproteinase and plasminogen activator-plasmin systems in angiogenesis. Arterioscler. Thromb. Vasc. Biol., 21, 1104-1117, 
2001.

[34] Schnaper, H.W., Grant, D.S., Stetler-Stevenson, W.G., Fridman, R., D'Orazi, G., Murphy, A.N., Bird, R.E., Hoythya, M., Fuerst, J.R., and French, D.L.: Type IV collagenase(s) and TIMPs modulate endothelial cell morphogenesis in vitro. J. Cell. Physiol., 156, 235-246, 1993.

[35] Itoh, T., Tanioka, M., Yoshida, H., Yoshioka, T., Nishimoto, H., and Itohara, S.: Reduced angiogenesis and tumor progression in gelatinase A-deficient mice. Cancer Res., 58, 1048-1051, 1998.

[36] Kato, T., Kure, T., Chang, J. H., Gabison, E.E., Itoh, T., Itohara, S., and Azar, D.T.: Diminished corneal angiogenesis in gelatinase A-deficient mice. FEBS Lett., 508, 187-190, 2001.

[37] Annabi, B., Lachambre, M-P., Bousquet-Gagnon, N., Page, M., Gingras, D., Beliveau, R.: Green tea plyphenol (-)-epigallocatechin 3-gallate inhibits MMP-2 secretion and MT1-MMP-driven migration in glioblastoma cells. Biochim. Biophys. Acta, 1542, 209-220, 2002.

[38] Demeule, M., Brossard, M., Page, M., Gingras, D., and Beliveau, R.: Matrix metalloproteinase inhibition by green tea catechins. Biochim. Biophys. Acta, 1478, 51-60, 2000.

[39] Dell'Aica, I., Dona, M., Sartor, L., Pezzato, E., Garbisa, S.: (-)Epigallocatechin-3-gallate directly inhibits MT1-MMP activity, leading to accumulation of nonactivated MMP-2 at the cell surface. Lab. Invest., 82, 1685-1693, 2002.
[40] Jankun, J., Selman, S., and Swiercz, R.: Why drinking green tea could prevent cancer. Nature, 387, 561, 1997.

[41] Wei, H., Zhang, X., Zhao, J.F., Wang, Z-Y., Bickers, D., and Lebwohl, M.: Scavenging of hydrogen peroxide and inhibition of ultraviolet light-induced oxidative DNA damage by aqueous extracts from green and black teas. Free Radic. Biol. Med., 26, 1427-1435, 1999.

[42] Lin, J.K., Liang, Y.C., and Lin-Shiau, S.Y.: Cancer chemoprevention by tea polyphenols through mitotic signal transduction blockade. Biochem. Pharmacol., 58, 911-915, 1999.

[43] Kuroki, M., Voest, E.E., Amano, S., Beerepoot, L.V., Takashima, S., Tolentino, M., Kim, R.Y., Rohan, R.M., Colby, K.A., Yeo, K-T., and Adamis, A.P.: Reactive oxygen intermediates increase vascular endothelial growth factor expression in vitro and in vivo. J. Clin. Invest., 98, 1667-1675, 1996.

[44] Fukuda, S., Motomiya, Y., Chida, M., Ueda, Ta., Ueda, To., Arai, Y., Naka, H., Kuriyama, H., Awata, T., Yamamoto, Y., Armstrong, D., and Koide, R.: Corneal neovascularization induced by lipid hydroperoxide is inhibited with a new antioxidant (EPC-K1). Invest. Ophthalmol. Vis. Sci., 38, s513, 1997.

[45] Ueda, Ta., Ueda, To., Armstrong, D., Arai, Y., Takano, Y., Kitashiro, R., Shirota, Y., Ogino, D., Fukuda, S., Yamamoto, Y., Chida, M., Koide, R., and Yasuhara, H.: Effect of Sairei-to, Gorei-san or Shosaiko-to on lipid hydroperoxide-induced corneal neovascularization. J. Eye, 15, 1303-1307, 1998. 